\title{
Whiteboards: One tool to improve patient flow
}

Wendy Chaboyer, $\mathrm{PhD}, \mathrm{RN}$

Director and Professor, Research Centre for Clinical and Community Practice Innovation, Griffith University, Gold Coast, Queensland, Australia

Karen Wallen, MN

Research Centre for Clinical and Community Practice Innovation

Griffith University

Marianne Wallis, PhD, RN

Professor, Research Centre for Clinical and Community Practice Innovation and the Gold Coast Hospital, Queensland, Australia

Anne McMurray, , $\mathrm{PhD}, \mathrm{RN}$

Professor of Nursing, Murdoch University, Mandurah, Western Australia, Australia

Corresponding Author: Professor Wendy Chaboyer

Research Centre for Clinical and Community Practice Innovation, Griffith University, Gold Coast, Queensland, Australia, 4222

Phone: 755528 518,

Fax: 755528526

W.Chaboyer@griffith.edu.au

Reprints:

Acknowledgement:

Competing interests:
Professor Wendy Chaboyer

The Australian Commission on Safety and Quality in Health Care provided the funding for this study.

Financial support was provided by the Australian Commission on Safety and Quality in Health Care but this did not pose a competing interest as they were not involved in the study design, data collection, analysis, interpretation or in writing of the article. 
Whiteboards: One tool to improve patient flow

Wendy Chaboyer, PhD, RN

Director and Professor, Research Centre for Clinical and Community Practice Innovation, Griffith University, Gold Coast, Queensland, Australia

Karen Wallen, MN

Research Centre for Clinical and Community Practice Innovation

Griffith University

Marianne Wallis, $\mathrm{PhD}, \mathrm{RN}$

Professor, Research Centre for Clinical and Community Practice Innovation and the

Gold Coast Hospital, Queensland, Australia

Anne McMurray, , PhD, RN

Professor of Nursing, Murdoch University, Mandurah, Western Australia, Australia

Corresponding Author: Professor Wendy Chaboyer

Research Centre for Clinical and Community Practice Innovation, Griffith University, Gold Coast,

Queensland, Australia, 4222

Phone: 755528 518,

Fax: 755528526

W.Chaboyer@griffith.edu.au

Reprints:

Acknowledgement:

Competing interests:
Professor Wendy Chaboyer

The Australian Commission on Safety and Quality in Health Care provided the funding for this study.

Financial support was provided by the Australian Commission on Safety and Quality in Health Care but this did not pose a competing interest as they were not involved in the study design, data collection, analysis, interpretation or in writing of the article.

Word Count: 2,500 


\begin{abstract}
Objective: To describe the integration of whiteboards into unit routines in one Queensland Health Service District (HSD).

Design and setting: A case study of three in-patient wards, two medical, one surgical, in a university affiliated regional teaching hospital and one day clinic in the same HSD was used. Data collection included 45 hours of observation of 4 whiteboards and 62 staff over 2 months, 11 in-depth interviews with nursing and allied health staff and several photographs of the whiteboards in mid 2008.
\end{abstract}

Main outcome measures: Qualitative analysis of the structures, processes and perceived outcomes of the use of whiteboards.

Results: The physical configuration of the whiteboards did not vary, however their content and usage by various professional groups fluctuated. Whiteboards were most successfully integrated in the clinic, where they became an integral part of multidisciplinary rounds, and were updated and referred to several times each day. They were partially integrated into the two medical wards, with various health professionals updating and referring to the whiteboard. On the surgical ward an assistant in nursing updated the whiteboard but it was not referred to by others. Staff in the clinic and on the medical wards perceived that whiteboards facilitated timely referrals, improved patient flow and enabled timely and better discharge planning but surgical nursing staff described them as an imposition and a cause of conflict among clinical team members.

Conclusions: Whiteboards have the potential to improve patient flow but a planned approach to their use is required. Issues related to the use of whiteboards including staff buy-in, discharge planning and patient privacy need to be addressed. 
Keywords: Whiteboard, Communication tool, Interdisciplinary communication, Patient flow, Discharge planning 


\section{Whiteboards: One tool to improve patient flow}

A focus on both quality and efficiency in health care has led to the implementation of innovations such as patient flow teams, bed managers and various support tools $(1,2)$. The traditional whiteboard is a low technology, low cost and low maintenance tool. Whiteboards can be an efficient method to document patient status and progress $(3,4)$. They may assist in timely completion of patient care activities and improve communication and teamwork, both within and across disciplines (4,5). They allow the sharing of information without the need for face to face meetings (6), however they can also be used in a manipulative way, controlling access to information and workflow $(4,7)$. Little attention has been paid to what influences successful integration of whiteboards into unit routines. In order to better understand the use of whiteboards, we describe their structures, processes, and perceived outcomes and contrasts successful from unsuccessful integration into unit routines.

\section{METHODS}

A case study method (8) with four nested cases in one Queensland Health Service District (HSD) was used. Donabedian's (9) framework was used to conceptualise the study. It is comprised of three elements; structure, process and outcome, to frame the quality evaluation of health service performance. Assessing quality is undertaken by appraising structures and processes and linking these to outcomes, with the assumption that structures influence processes that in turn influence outcomes. Structures include the physical and organisational properties processes are what is actually done, and outcomes are what is accomplished (10). Evaluating an aspect of quality is aimed at causal relationships between the three elements; that is, the structures and processes are responsible for outcomes $(9,10)$. 


\section{Setting}

The study took place on three in-patient wards, two medical, one surgical, in a university affiliated regional teaching hospital and one day clinic in the same HSD about 10-12 months after the whiteboards were installed. In the clinic, where patients had to be seen by a number of health professionals, nursing staff suggested to the rest of the multidisciplinary team that a whiteboard might help share patient progress information. All groups were then involved in the planning, training and implementation phases. In the hospital, installation occurred because an examination of patient flow identified a number of issues related to referrals and discharge planning and a lack of standardisation of work routines across units. When the idea of a whiteboard was raised by the patient flow team, it was embraced by the medical nurses. Shortly thereafter, it was rolled out throughout the hospital. A nurse unit manager (NUM), seconded to the patient flow initiative, led this roll out and training sessions were delivered to doctors, NUMs and allied health professionals.

\section{Sample}

Participants were purposively chosen for interviews with the aim of achieving variation in type of worker and type of unit. The focus of the observations was individuals who either reviewed or wrote on the four whiteboards, with some of them also being interviewed. Ethics approval was obtained from two human research ethics committees. All participants consented to participate in the study, Patient consent was not required. 


\section{Data Collection}

We used three forms of data collection; in depth semui-structured audio-taped interviews, semi-structured observations, and photographs of the whiteboards on each unit. The interviews were the primary source of data, with the observations and photographs used as a triangulation technique to substantiate understandings. Interview questions explored the implementation and use of whiteboards. Examples of interview questions include: What do you think is the purpose of the whiteboard? What do you think should be written on the whiteboards? How do you refer to the whiteboard? Participants were interviewed in a quiet location in the hospital. Interviews were transcribed verbatim and checked for accuracy. Observations focused on the structures and processes that surrounded the whiteboard use including who wrote on the whiteboard and when, who read it, and types of staff interactions at the whiteboard. They were recorded on a semi-structured data collection form. As a visual record, photographs aided in understanding whiteboard structures.

\section{Data Analysis}

Data were analysed using the case analysis technique (8). Case analysis involves an iterative explanation-building process. The objective is to refine a set of ideas and link these to the data. First, data were categorised into the domains of structures, processes and perceived outcomes. Structures were defined, and then propositions about differences in engagement or use of the whiteboard were generated. Processes and outcomes were identified from comparisons of use across cases. Data analysis continued until a final set of explanations were generated. With each iteration there was constant reference to the original purpose of the inquiry and attempts were made to consider alternative, plausible explanations (8). One researcher led the analysis, 
with other researchers meeting to scrutinize, discuss and question the preliminary findings to refine the quality of the analysis.

\section{RESULTS}

Over 2 months a total of 11 participants were interviewed and 45 hours of observation was undertaken. A total of 62 staff (40 nurses, 11 doctors, 10 allied health professionals and 1 nursing assistant) were observed engaging in some way with the whiteboard, generally writing on it or reviewing it. The interview sample was comprised of 5 registered nurses, 4 allied health professionals and 1 one assistant in nursing with one other declining to be identified (Table 1). All doctors who were approached to be interviewed declined, citing work pressures as their reason. All others who were approached agreed to be interviewed. Just under half (46\%) of the participants interviewed were nurses and slightly more than a third (36\%) were allied health professionals. Most worked full time. Figure 1 summarises the structures, processes and outcomes identified in this research. They are described next, with a focus on the contrasts between successful and unsuccessful integration into ward routines.

\section{$\underline{\text { Structures }}$}

Four structural elements of whiteboard communication were identified; their physical properties, their physical location, concurrent permanent documentation and the staff who used them. All whiteboards were the same dimensions; $280 \mathrm{~cm}$ horizontal by $200 \mathrm{~cm}$ vertical. They were divided into columns for bed numbers, consultant doctors, common allied health referrals, diagnostic tests, discharge medications, and expected 
date of discharge. Two different coding systems were used to indicate referrals (Table 2).

All whiteboards were located in high traffic areas. On the three in-patient wards they were near the single nurses' station and were readily visible by staff, patients and visitors. Participants explained that after consultation with the hospital's legal department regarding patient confidentiality, bed numbers and not names or initials were used. In the clinic the whiteboard was located away from the view of patients and visitors and thus, contained more detailed information, which appeared to make it particularly useful. Easy visibility for staff appeared to be important for its use.

Some form of concurrent permanent documentation, either paper or electronic, was developed on the in-patient wards, which reflected information that had to become a permanent part of the patient's health record or information that was required to be transmitted to others when patients were transferred from unit to unit. One nurse commented:

$$
\begin{aligned}
& \text { "We use a referral form ... if the patient did move the information would } \\
& \text { still be documented there ... yes you might say that's a duplication, but it's a } \\
& \text { slight safety check." }
\end{aligned}
$$

In the clinic doctors, nurses and allied health professionals interacted with the whiteboard both individually and as a team. On the medical wards doctors, nurses and allied health interacted with it, individually and occasionally together. On the surgical ward only a nursing assistant was observed to interact with the whiteboard, writing patient information on it. 


\section{$\underline{\text { Processes }}$}

Two processes were identified: training staff in the use of whiteboards; and integrating whiteboards into daily routines. Small and large group training was delivered to staff with a focus on the results of the patient flow project and an explanation of how the whiteboards could both standardise and improve ward routines. After this initial training, there was no ongoing training, which meant that some new and rotating staff did not receive training. This was not problematic in the clinic due to limited staff turnover but may be a reason it was not really used on the surgical ward. In the clinic and medical wards staff described how they were involved in the planning phase, which they viewed as key for its successful integration into work routines. Surgical nursing staff commented that they did not have input in its planned use nor did they actively interact with it, despite the training session.

Integration of the whiteboards into unit routines was accomplished in varying degrees. In the day clinic, nurses, doctors and allied health staff inspected and updated the whiteboards regularly throughout the shift and multidisciplinary clinic rounds were physically located at the whiteboard. One allied health professional said:

"It's a visual way of communicating with all the different allied health (staff) that we would easily see when we came on the ward"

On the medical wards, information was generally updated by nurses. Doctors, nurses and allied health professionals referred to the whiteboards individually but doctors did not integrate them into their rounds. On the surgical ward, a nursing assistant, was observed writing information on the whiteboard, but no other staff members were 
observed looking at it, findings that were supported by interview data. The nursing assistant stated that to her knowledge only the bed manager used the whiteboard.

\section{$\underline{\text { Outcomes }}$}

The major outcome we identified was the perception that whiteboards facilitated timely referrals, improved patient flow and enabled timely and better discharge planning, such as writing discharge medication scripts. A nurse noted:

"Its about trying to get discharges happening in a timely manner. There is a whole set of processes that also need to happen not just the doctor part of it all but all the additional services that have to kick in ahead of time in order for a patient to be discharged appropriately."

Participants from the clinic viewed the whiteboard as a vital tool that helped the multidisciplinary team communicate with each other and, at the end of the day, erasing the whiteboard signalled completion of the day's work. Implementation was not successful on the surgical ward, where the whiteboards were viewed as an imposition and a cause of conflict among various professional groups.

\section{DISCUSSION}

The patient centred nature of whiteboard use is aligned with current trends in information transfer. Having health professionals document information in a way that is readily visible can facilitate accurate and appropriate clinical judgements. In the context of information sharing, whiteboard use also has the capacity to promote teamwork and accountability (6), particularly with timely scrutiny of one another's plans and reports (4). As a result of this study, three key issues surrounding the use of 
whiteboards have emerged; staff buy-in, discharge planning and finally, patient privacy.

In order for whiteboards to be effective communication tools, staff buy-in is imperative. There needs to be a powerful, guiding coalition to effect change, and this is best achieved with joint, multidisciplinary, systematic planning on the basis of shared goals and a shared vision (11). This study showed that when staff perceived they did not have a part of planning and implementation, they did not develop ownership of it nor did they see it as a tool, rather it was a burden and extra work, that caused conflict. This finding highlights the importance of a planned approach to change. Establishing a sense of urgency for change on the basis of patient safety and ensuring that this is communicated widely at the ward and institutional levels can be persuasive for staff members who may initially be resistant to change (11).

The notion that the whiteboard facilitated patient flow and discharge planning was a consistent finding and has been recognised previously $(7,12)$. Our findings are consistent with Xiao and colleagues' (5) description of how whiteboards supported collaborative work in the emergency department. Whiteboards allow tasks to be articulated, managed and tracked. They assist in resource planning such as bed availability and facilitate both synchronous (i.e. the message is sent and received at the same time) and asynchronous (i.e. the receiver decides when to receive the message) communication (13). Others have noted that whiteboards and other communication tools such as electronic dashboards can actually be used to control practice $(4,7,13)$, however, our study did not highlight the 'game playing' others have noted $(4,6)$. 
Although, joint medical and nursing rounds may shorten hospital length of stay $(15,16)$, they did not occur on the three in-patient wards we studied. In such instances, the potential for the whiteboard to act as synchronous or asynchronous communication channel are unlikely to be realised unless short updates between doctors and nurses occur at it or doctors record their plans on it. Given their workloads, it is no wonder that doctors, nurses and allied health professionals find this difficult. In previous research, health professionals have argued that because of time restraints, the need for efficient and relevant information sources is imperative to support collaboration and information needs in patient care (3). It seems self evident that the information must also be accurate, thus if whiteboards are used, there must be a clear line of responsibility for updating the information it contains. Further, making whiteboard reviews part of ward rounds formalise its use into ward routines.

Somewhat surprisingly, the issue of patient privacy and confidentiality of information did not feature in our findings. However, the state's confidentiality guidelines (17) and the hospital's legal department were consulted in the planning phase to address issues related to patient privacy. Unlike other hospitals, where patients' names are recorded (7), the NUMSs in the hospital we studied made the decision to use bed numbers only as the reference. It is self-evident that the physical location of the whiteboards may be a significant factor related to patient privacy, but finding appropriate locations for them may be difficult.

While this study provides some new insights into the integration of whiteboards in hospitals, it has a number of limitations. First, it was conducted in one health service 
district only, thus contextual issues may limit its generalisability. However, four diverse units were used with wide variation in how the whiteboards were used, providing a rich breadth of data. Second, a key professional group, medical doctors, declined to be interviewed. There is no way to know how their perceptions may have influenced the data analysis and emerging findings. Finally, we obtained participants' perceptions of perceived benefits, thus it may be that things like the referral and discharge process may not have actually improved. Future researchers may be able to assess these potential outcomes using data routinely collected and held in administrative databases.

In conclusion, this case study of the use of whiteboards in four units in one health service district showed that whiteboards facilitated timely referrals, improved patient flow and enabled timely and better discharge. However, for whiteboard to be integrated into units' routines, staff need to believe they have been involved in the planning phase, and require access to training in their use. Importantly, careful consideration of issues surrounding confidentiality of information can overcome potential breeches to patient privacy. 


\section{References}

1. Gygi C, DeCarlo N, Williams B. Six Sigma for dummies. Indianapolis: Wiley, 2005.

2. Hines P, Rich N. The seven Value Stream Mapping tools. Int J Operations Prod Manag, 1997; 17: 44-62.

3. Mendonca, EA, Chen ES, Stetson PD, et al. Approach to mobile information and communication for health care. Int J Med Inform 2004; 73: 631-638.

4. Riley R, Forsyth R, Manias E, Iedema R. Whiteboards: Mediating professional tensions in clinical practice. Communication \& Med 2007; 4: 165-175.

5. Xiao Y, Schenkel S, Faraj S, et al. What whiteboards in a trauma centre operating suite can teach us about emergency department communication. Ann Emerg Med 2007; 50: 387-395

6. Coier E, Tombs V. Communication behaviours in a hospital setting: An observational study. BMJ 1998; 316: 673-676.

7. Heartfield M Regulating hospital use: Length of stay, beds and whiteboards. Nurs Inquiry 2005; 12: 21-26.

8. Yin R. Case study research: Design and methods (3rd ed). Thousand Oaks CA: Sage, 2003.

9. Donabedian A (1969). Medical care appraisal - quality and utilization. In, American Public Health Association (ed), A guide to medical care administration, Vol 2. Washington: APHA.

10. Donabedian A. The role of outcomes in quality assessment and assurance. Quality Rev Bull 1992; 18: 356-360.

11. Kotter J. Leading change: why transformation efforts fail. Harvard Business Review 1995; 73:59-67. 
12. Boger E. Electronic tracking board reduces ED patient length of stay at Indiana Hospital. J Emerg Nurs 2003; 29: 39-43.

13. Stead WW, Patel NR, Starmer JM. Closing the loop in practice to assure the desired performance. Trans Amer Clinical Climatol Assoc 2008; 119:185-94.

14. Dayton E, Henriksen K. Communication failure: basic components, contributing factors, and the call for structure. Jt Comm J Qual Patient Saf 2007; 33(1): 34-47.

15. Curley C, McEachern JE, Serroff T. A firm trial of interdisciplinary rounds on inpatient medical wards. Medical Care 1998; 36(8 Suppl): AS4-AS12.

16. Jitapunkel S, Nuchprayoon C, Aksaranugraha S et al., A controlled clinical trial of multidisciplinary team approach in the general medical wards of Culalongkorn Hospital. J Med Assoc Thai 1995; 78(11): 618-623.

17. Queensland Health. Part 7 Confidentiality guidelines. Brisbane, Queensland Government 2006. 


\section{Structures}

- Physical attributes of the whiteboard

- Location of the whiteboard

- Concurrent permanent documentation

- Staff (medical, nursing, allied health)

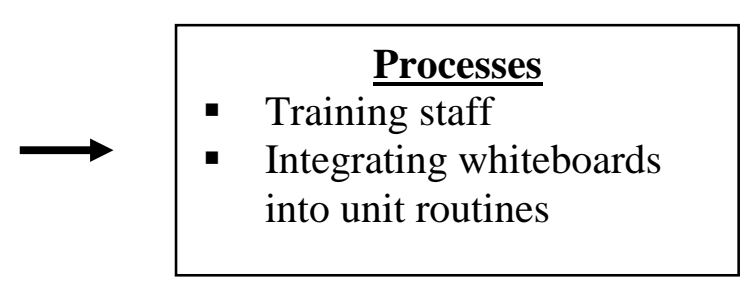

\section{Outcomes}

- Facilitates timely referrals

- Improves patient flow

- Enables timely and better discharge planning

Figure 1: Overview of the Structures, Processes and Perceived Outcomes of Whiteboard Use 
Table 1: Characteristics of the Participants

\begin{tabular}{lc}
\hline Characteristic & Frequency \\
& $\mathrm{n}=11$ \\
\hline Participant group & 1 \\
RN (bedside) & 4 \\
Nurse managers or educators & 4 \\
Allied healthcare professionals & 1 \\
Assistant in nursing & 1 \\
Information declined & \\
\hline Age group (years) & 2 \\
$<30$ & 3 \\
$30-<40$ & 3 \\
$40-<50$ & 3 \\
\hline 50 & 10 \\
\hline Full-Time & \\
\hline
\end{tabular}


Table 2: Two Examples of Whiteboard Codes

\begin{tabular}{llll} 
Code & Meaning & Code & Meaning \\
\hline & $\begin{array}{l}\text { Referral request has been } \\
\text { made }\end{array}$ & $X$ & Action Required \\
Referral accepted; patient is & Completed \\
being assessed and/or treated & & \\
\hline
\end{tabular}

